\title{
Terahertz Inspection of Buildings and Architectural Art
}

\author{
Kirsti Krügener ${ }^{1}$, Jan Ornik ${ }^{2}$ (D), Lorentz M. Schneider ${ }^{2}$, Alexander Jäckel ${ }^{2}$, \\ Corinna L. Koch-Dandolo ${ }^{3}$ (D), Enrique Castro-Camus ${ }^{4}, *$ (D) Nicole Riedl-Siedow ${ }^{5, \dagger}$, \\ Martin Koch ${ }^{2}$ (D) and Wolfgang Viöl ${ }^{1}$
}

1 Faculty Engineering and Health , HAWK University of Applied Sciences and Arts, Von-Ossietzky-Str. 99, 37085 Goettingen, Germany; kirsti.kruegener@hawk.de (K.K.); wolfgang.vioel@hawk.de (W.V.)

2 Department of Physics and Material Sciences Center, Philipps-Universität Marburg, Renthof 5, 35032 Marburg, Germany; jan.ornik@physik.uni-marburg.de (J.O.); schneid4@staff.uni-marburg.de (L.M.S.); alexander.jaeckel@physik.uni-marburg.de (A.J.); martin.koch@physik.uni-marburg.de (M.K.)

3 Independent Researcher, 6962 Viganello, Switzerland; corinnakd@thz.org.mx

4 Centro de Investigaciones en Optica A.C., Loma del Bosque 115, Lomas del Campestre, Leon, Guanajuato 37150, Mexico

5 Faculty of Architecture, Engineering and Conservation, HAWK University of Applied Sciences and Arts, Bismarckplatz 10/11, 31135 Hildesheim, Germany; notpossible@impossible.com

* Correspondence: enrique@cio.mx

+ IN MEMORIAM: This article is dedicated to the work and life of Prof. Dr. Nicole Riedl-Siedow (1971-2017), who promoted and enriched the cooperation of researchers in the field of conservation of mural paintings and application-oriented disciplines through her knowledge of cultural heritage and its preservation. In particular, the preservation of the facade paintings of the Basilica of Constantine in Trier was a major concern of hers, in which she invested a lot of energy and time in her research and work as a restorer. We are therefore pleased to be able to present a part of her work in this article.

Received: 3 July 2020; Accepted: 23 July 2020; Published: 27 July 2020

\begin{abstract}
We present a broad literature review on the uses of terahertz radiation for the inspection architectural art, as well as building structures. As an example of the uses of terahertz in this field, we also include original results on a non-destructive assessment of a conservation intervention on murals of the Konstantinbasilika in Trier, Germany while using terahertz time-of-flight spectroscopy.
\end{abstract}

Keywords: terahertz; architecture; art

\section{Introduction}

Electromagnetic waves in the frequency region between $300 \mathrm{GHz}$ and $10 \mathrm{THz}$ (wavelenght between $30 \mu \mathrm{m}$ and $1 \mathrm{~mm}$ remained unexplored until about three decades ago, when ultrafast lasers were introduced [1]. Since then, this band of the electromagnetic spectrum, known as terahertz (THz) radiation or T-Rays, has found a plethora of applications in both scientific disciplines that range from semiconductor physics [2], to chemistry [3] and biology [4], to non-destructive testing in many fields, such as industry [5], and even in cultural heritage inspection [6]. Terahertz waves have three characteristics that make it very attractive for the inspection of culturally valuable objects: 
1. It penetrates a broad selection of materials, including textiles, polymers, ceramics, pigments, wood, etc.

2. It is non-ionizing, therefore it represents no occupational hazard to the users of this technology, and to the chemical, and therefore aesthetic, integrity of artworks.

3. It can produce cross-sectional images of layered structures, such as the ones present in multi-layer paintings.

Since about 20 years ago, a hand-full of research groups around the world have explored the potential of terahertz for the inspection of many forms of art, which go from oil-on-canvas paintings to mummies, and even a few examples of architectural art. Furthermore, a few examples of demonstrations of this same technique in the evaluation of the structural integrity of buildings have been presented. In this article we will present an overview of therahertz technology, followed by a detailed literature review of applications of T-Rays in architectural art and structural inspection. Finally, we present some new results of our own, in which we monitored in-situ the evolution of a conservation intervention on some murals from the Konstantinbasilika in Trier, Germany.

\section{Overview of Terahertz Technology}

Terahertz time-domain spectroscopy (THz-TDS) was first demonstrated in 1988 by Smith and coworkers [7] who used a colliding pulse mode-mocked dye laser to gate photoconductive antennas on the basis of radiation damaged silicon-on-sapphire (SOS). Grischkowsky improved this technique, such that it allows for high-quality spectroscopy in the lower terahertz range [8]. Further improvements became possible with the advent of mode-locked titanium sapphire in the early 1990s and the use of low-temperature grown GaAs (LT-GaAs) as antenna substrate.

Figure 1a illustrates the working principle of a typical free-space $\mathrm{THz}$ time-domain spectrometer: a Ti:sapphire laser that is pumped by a frequency doubled $\mathrm{Nd}: \mathrm{YVO}_{4}$ laser which produces $\sim 100 \mathrm{fs}$ pulses with a repetition rate of around $80 \mathrm{MHz}$. These laser pulses are used to gate both the generation and detection photoconductive antennas that consist of a semiconductor substrate and a pair of coplanar metal striplines. The laser pulse with a photon energy above the semiconductor's band gap energy is focused in between the two striplines. It optically excites electrons and holes. The striplines of the emitter antenna are biased, such that a constant field existed between them with a field strength of around $5 \mathrm{kV} / \mathrm{cm}$. The optically excited carriers are accelerated in this field, leading to a short current pulse that is the source of the emitted THz pulse. After passing through some optical components, such as silicon hyperspherical lenses, off-axis parabolic mirrors, and the sample, the transmitted THz radiation is focused onto the detector antenna, which also consists of two striplines on a semiconductor material. The detector gated by another $100 \mathrm{fs}$ laser pulse. The semiconductor material chosen for this antenna must have a very short carrier life time, such as SOS or LT-GaAs. In contrast to the emitter antenna, the optically excited carriers are not accelerated by an applied external field, but instead by the field of the incident $\mathrm{THz}$ pulse. This leads to a weak current which is amplified and monitored. By varying the delay between the gating laser pulse and the incoming $\mathrm{THz}$ pulse, one can sample the $\mathrm{THz}$ field via a cross correlation process. See [9] for details. In order to accumulate an image of the $\mathrm{THz}$ transmission though an extended object, one can, in the simplest case, translate the sample through the focus of the THz beam in a raster pattern [10]. An image is then acquired pixel-by-pixel. Yet, there have been several other schemes demonstrated over the years (see [11] for a review). 

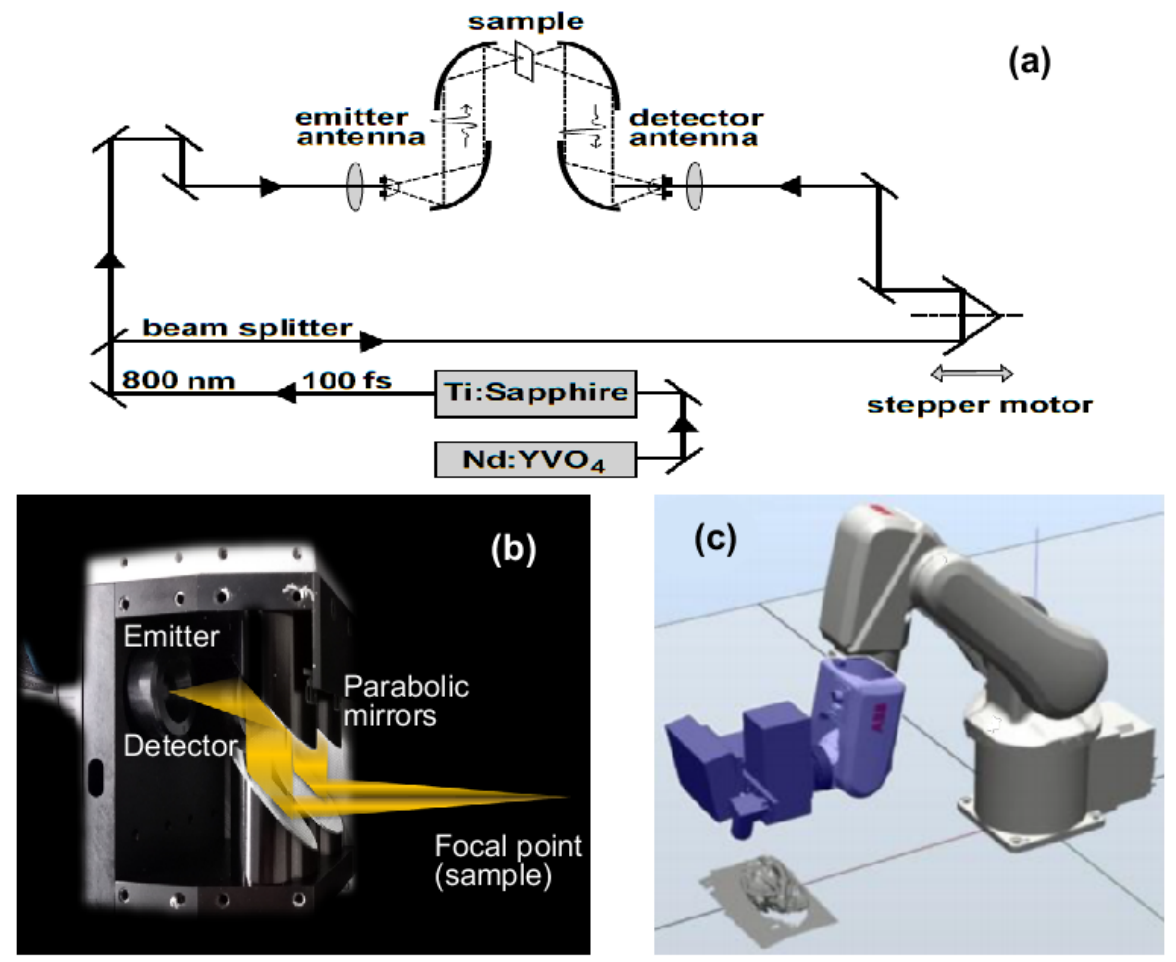

Figure 1. (a) Schematic of a free-space THz time-domain spectrometer in transmission geometry. (b) Schematic representation of a reflection geometry of a terahertz system. (c) Render of a THz reflection setup mounted on a robotic arm while doing a scan of an arbitrarily shaped object. Panels $(\mathbf{b}, \mathbf{c})$. Adapted with permission from E. M. Stübling PhD thesis, 2019 [12].

It is worth mentioning that, although all TDS systems operate conceptually in the manner that we explained here, most of the studies related to cultural heritage with terahertz have been performed with fiber-coupled TDS systems, in those cases, the Ti:sapphire laser is replaced by a rare-earth:fiber laser and most of the laser optics are implemented in optical fibers, instead of free-space. Picometrix were the first demonstrated fibre-coupled THz systems in the year 2000. Such systems allow to position $\mathrm{THz}$ antennas more freely. In 2007 Wilk and coworkers presented a THz-TDS system based on a cost-effective fibre laser operating at $1.55 \mu \mathrm{m}$ [13]. These lasers are based on low-cost telecom components developed for long-term operation. As antenna material, low-temperature grown InGaAs/InAlAs multiple-quantum wells were used. On the basis of this technology, a variety of different companies today offer fibre-coupled THz-TDS systems with a good signal to noise ratio and a reasonable bandwidth [14,15].

For $\mathrm{THz}$ measurements on buildings, a reflection geometry is needed. This technique was introduced in 1997 by Mittleman and it is called "THz tomography" [16]. Both beams, the one coming from the emitter that is focused onto the object under investigation and the one being reflected from the object and propagating to the receiver are focused or collimated, respectively, either with lenses or via off-axis parabolic mirrors, as shown in Figure 1b. At each interface between materials with different refractive index the pulses are reflected. From the pattern of theses "echoes", one can reconstruct the inner structure of the object. THz tomography is closely related to optical coherence tomography [17] and it has some similarities to ultrasound imaging, although sound waves are longitudinal pressure waves, while $\mathrm{THz}$ are transverse electromagnetic waves.

For many years $\mathrm{THz}$ tomography was limited to the investigation of flat samples that were moved through the focus of the beam in a raster pattern. In 2017, Stübling et al. introduced a fibre-coupled THz 
tomography unit attached to a robotic arm [18] as shown in Figure 1c. With this approach, the THz emitter and receiver can be positioned perpendicular and at defined distance to the sample surface. Hence, this system allows for the acquisition of reflection $\mathrm{THz}$ tomographic images of samples with an arbitrarily shaped surface.

\section{Terahertz Uses in Architectural Art}

The characterization of historical buildings is the key task for fields, such as conservation of architectural heritage, building science, and building archaeology. Today's architectural conservation practice involves scientific survey based on specialized diagnostic methodologies and techniques aimed at understanding the conditions of conservation of architectural pieces as well as construction techniques. When dealing with culturally valuable objects, non-destructive testing is, of course, preferred. The use of non-destructive methods of scientific investigation have rapidly expanded thanks to the development and refinements of portable instruments which allow to collect large quantities of highly relevant data without the need for physical sampling. In many cases such portable devices, have capabilities analogous to larger laboratory-based systems. The most common techniques used in these fields include photogrammetric and geodetic endoscopy, ultrasound and thermographic analysis, and laser scanning. Other studies, like multispectral and hyperspectral tests, special photographic techniques (IR- and UVbased photography), and X-ray fluorescence spectrometry (XRF) for elemental analysis [19] are used, and also Raman spectroscopy, near-infrared spectroscopy (NIR) [20], among others, have been incorporated in the conservators toolboxes.

Terahertz spectroscopy and imaging is a powerful analytical method that can provide unique information about the inspected object non-invasively and contactelessly. As a spectroscopic technique has the merit of contributing to material characterization, while as imaging technique with depth profiling capabilities can reveal finer stratigraphy and evaluate the structural characteristics and conservation conditions of the investigated target. The technique has been tested for the characterization of cultural heritage, architectural heritage, and decorations made with different types of building materials and from different regions. This section aims to illustrate the results obtained, so far, from these first investigations. Wall painting is, by far, the typology of cultural heritage most studied with this technique, and this theme will therefore be widely discussed.

\subsection{Wall Paintings}

Wall paintings are the oldest known form of figurative artwork dating back to the prehistoric period [21]. The conservation of wall paintings inevitably concerns not only the paintings themselves, but also the supporting architectures and building materials [22]. Detailed knowledge of the internal structure supporting a wall painting may be considered fundamental for conservation purposes, allowing for the localization of cracks and layers detachments, as well as for identification of regions where filling or consolidation is needed.

In historical Europe, wall paintings were typically executed on wet (fresco) or dry (secco) plaster painted with pigments dissolved in limewater (fresco) and/or with organic binders (secco). Several plaster or mortar layers typically cover the wall structure before the paint application, normally characterized by increasing thicknesses and coarseness starting from the supporting structure. Aggregates within the mortar or plaster may vary and include stone, sand, straw, fibers etc. It has been established that $\mathrm{THz}$ radiation is generally able to provide information about the interim region of a wall painting up to approximately one centimeter into a plaster wall surface (for $n=2.2$ ) [23]. However, this number needs to be adjusted, depending on the refractive index of the constituent material of the wall and the extent of the scattering effect caused by the granular surface and internal structure on the radiation. 
To the best of our knowledge, a terahertz time-domain system (Picometrix T-ray 4000) was used to study wall painting replicas for the first time by Jackson et al. in 2008 [24]. They imaged graphite preliminary sketches (underdrawing) covered by layers of paint and a top thick layer of gypsum plaster; they, thus, demonstrated the feasibility of using the terahertz technique for inspecting wall paintings, specifically for imaging underdrawing and paint layers covered by a plaster topping layer. The first report on a real wall painting scanned with a THz-TDS system was a fragment about $25 \mathrm{~cm}$ in the width of a wall painting from Dazhao Monastery (Mongolia). The remain, representing a bust of a woman, was scanned in 2010 by Fukunaga et al. [25]. The distribution of different materials on the painting surface was mapped and the painting stratigraphy was reconstructed from the terahertz measurements. The surface depiction was clearly imaged in the reflection $\mathrm{THz}$ image thanks to the contrast given by pigments with relatively high reflectance (minimum, cinnabar, and lead white) as compared to the other ones (smalt, orpiment, malachite, and red ochre) present in the panting. In addition, the layers composing the multilayered painting support, i.e., the fine preparation layer, coarse preparation layer and clay wall, were identified in the non-invasive $\mathrm{THz}$ cross-sections (B-scans).

When compared to other painting typologies, such as paintings on canvas and wooden panel, scanning wall paintings with a reflection $\mathrm{THz}$ time-domain system is complicated by the fact that walls are typically rough and uneven, thus deviating the $\mathrm{THz}$ beam reflected at the surface from the detector and causing beam defocusing in the optical axis direction. In addition, the typical grain-like structure of wall painting surfaces causes scattering of $\mathrm{THz}$ waves, strongly influencing the output of the measurements. In fact, the spatial scale of refractive index fluctuations due to variations in surface roughness can be, in many cases, comparable to the wavelength of the THz signal.

Walker et al. [26] have defined a correction procedure for adjusting the $\mathrm{THz}$ data acquired by scanning the uneven wall paintings of the dwellings at the Neolithic Çatalhöyük archeological site (Turkey). THz scans were performed in a "pitch-catch" configuration. They first created a $(x, y, z)$ three-dimensional surface profile based on the time delay difference of reflected signals from a zero plane defined by the time shift of the signal which gave the largest amplitude. After converting the profile into a spherical coordinate system, deviations from the focal plane have been computed in the zenith, azimuthal, and orthogonal projection dimensions. The resulting propagation of the beam to wall surface and its deflection from the optimum line of reflection were calculated and the misalignments were used to evaluate the overlap integral describing the coupling between the displaced reflected beam and the detector, which has been, in turn, used to correct the data for the percentage of radiation deviated from the detector.

Fukunaga et al. [27] studied the scattering effect caused by the mortar sand aggregates found in most of the wall paintings, whose presence prevents the $\mathrm{THz}$ radiation from penetrating deep into the wall. For the study, they created replicas of the wall paintings and scanned them with a terahertz time-domain system, such a study included a variety of styles of wall paintings, such as Pompeian, Etruscan, Byzantine, Buon Fresco, Sgraffiti, Egyptian, and Japanese. These kinds of wall paintings differ significantly in terms of materials used as support, preparation and paint layers. In addition to wide variations of the layer thicknesses and painting techniques. Significant results were obtained by analyzing $\mathrm{THz}$ B-scans. In all models, the THz reflections from the surface were more than ten times larger than those from internal boundaries. Yet, the $\mathrm{THz}$ reflection pulses were found above noise level in the layer, including large aggregate particles. Because the wavelength of the $\mathrm{THz}$ waves is comparable to the size of the sand particles $(\sim 1 \mathrm{~mm})$, scattering in layers rich in sand becomes strong and prevents $\mathrm{THz}$ waves from propagating deep into them. Thus, THz B-scans obtained from replicas having large sand aggregates were not clearly representing the internal structure, owing to high scattering. Small echoes appearing on the recorded THz depth profiles have been related to changes of the layers' porosity or to interfaces between mortar with different aggregates. 
Since the first applications, $\mathrm{THz}$ time-domain imaging has been employed on wall paintings for inspecting their structure and conservation state as well as for visualizing hidden depictions. Historically, it is, in fact, not rare to find wall paintings that have been overpainted or covered over time, hiding the original representation, for aesthetic or conservation reasons. Concerning hidden paintings, analyzes of $\mathrm{THz}$ B-scans have been proficiently used to detect subsurface depictions and underdrawings. The results in this sense have been obtained by Walker et al. [23] by THz scanning real wall paintings of different European Cathedrals, for instance, the Chartres Cathedral (France), the Riga Dome Cathedral (Latvia), and the Chartreuse du Val de Bénédiction (France) with a time-domain systems. Wall paintings of Chartres and Riga Cathedrals were covered by layers of plaster (Chartres) or lead white paint (Riga), while underdrawings sketched with sinopia were known to be under the paint layers of the paintings of the Church in Chartreuse du Val de Bénédiction. THz B-scans gave evidences about the presence of subsurface layers (Chartres and Riga), but also about subsurface layers losses (Riga). At Chartreuse, Sinopia underdrawing seemed to be detected in the THz B-scans at approximately $1 \mathrm{~mm}$ deep, together with the uneven stone surface upon which the wall plaster was applied, at depths calculated between $8-15 \mathrm{~mm}$.

Jackson B., Mourou G., Menu M., and Detalle V. used a THz time-domain system to scan a XIX century wall painting, Trois homes armés de lances, in the Louvre's Campana collection. As reported in a ScienceDaily article [28], Campana was an Italian art collector and art historians who is believed to have painted the current depiction on a previous Roman fresco that was removed from its original location in Italy and entered his collection. The $\mathrm{THz}$ research team was able to image the previous ancient Roman fresco underneath the current depiction.

Radpour R. et al. [29] used a reflective pulsed THz medical imaging system based on direct detection to acquire imagery of painted plaster samples in order to assess the ability of the system to image the Byzantine wall paintings at the Enkleistra of St. Neophytos in Paphos (Cyprus). The walls of the Enkleistra feature several painting phases spanning from the XII to the XVIII century. The various painting phases are separated from each other by a thin plaster layer or a lead white paint. For the research, they prepared several wall painting mock-ups of both fresco and secco techniques. The two relevant samples were secco samples painted in the shape of a cross respectively with cinnabar and minimum and later obscured by lead-white and chalk (minimum). A stark contrast between the paintings and surrounding plaster material was observed in the $\mathrm{THz}$ pictures for both the pigments used. Despite the strong scattering of $\mathrm{THz}$ radiation by a covering chalk layer, the $\mathrm{THz}$ image of the minimum based paint obscured by the chalk reveals the major part of a four-arm cross while apart, one of the four arms, was not clearly imaged possibly due to an uneven application of the paint and/or uneven surface of the plaster. By utilizing the system's confocal-like features, they acquired multiple THz images of the cinnabar based paint obscured with lead-white at increasing focal point locations (z values). Only partial images of the cross were visible at each $\mathrm{z}$ value, yet, a more complete $\mathrm{THz}$ image of the cross was obtained by combining the multiple $\mathrm{THz}$ z-scans, demonstrating how this method serves to better visualize hidden layers that are not perpendicular to the $\mathrm{THz}$ signal. The study on replicas demonstrate the feasibility of an in-situ investigation of the Byzantine paintings at Enkleistra. Reflection terahertz time-domain method has been used to obtain important information about plaster and internal structure of wall paintings, helping in determining their manufacturing and conservation state.

Inuzuka M. et al. [30] used a time-domain $\mathrm{THz}$ system to examine the plaster layer condition of the mural paintings of the Takamatsuzuka tumulus (Nara, Japan, end of VII beginning of VIII century). The paintings decorated the walls and ceiling made by tuff blocks and they are covered by few millimeters of plaster. For conservation reasons, in 2007 the stone chamber was disassembled and transported to a controlled environment space located near the Tumulus. The concerns were about the change of the hygrometric conditions from the old to the new location and the related reduced water content of the plaster, which caused material weakening and layer detachments because of its contraction. From the THz 
mesaurements, the areas where the plaster layer was well attached to the substrate, the reflection at the boundary of the plaster, and tuff stone could not be observed in the THz B-scans probably due to the similar refractive indices of both materials and to the absorbance of the reflected pulse. However, other regions displayed in the B-scans showed small reflected $\mathrm{THz}$ pulses displayed beneath the superficial one, indicating that the plaster layer had detached from the tuff stone, creating an air gap in between them. THz C-scans representing the absolute intensity integrated over increasing time intervals showed the subsurface air gap distribution within the scanned area. The detachment locations that were extracted in this manner were consistent with the ones recognized using other techniques by the restorers. Therefore, the terahertz imaging technique was proven to be a suitable method for noninvasive investigation of the conditions of a plaster layer.

Koch Dandolo and Jepsen [31] demonstrated the possibility to three-dimensionally (3D) visualize the surface profile of building elements buried inside the wall plaster by means of THz time-of-flight plot (ToF) and the volume rendering technique. An extended area of the apsidal Medieval wall painting of Nebbelunde Church (R $\phi$ dby, Lolland, Denmark) was scanned with a THz time-domain system. B-scans revealed the presence of two major in-depth anomalies. The first one was located at about $1 \mathrm{~cm}$ below the surface and positioned transverse at a steep angle into the plaster. The sign of the THz signals reflected at the anomalous interface indicated that the related material must have had a lower refractive index than the surrounding mortar. ToF offered additional insight by imaging, in detail, its surface morphology. The extremely sharp and regular texture of the buried interface indicated that it was not an accidental air gap, but rather a building element. The second anomaly was found at about $7-8 \mathrm{~mm}$ depth inside the plaster and it has been visualized in a volume rendering after data processing, first by windowing the relevant region of interest of the signals. Volume rendering allowed localizing the buried feature with respect to the wall painting surface. The sign of the reflected $\mathrm{THz}$ signal suggested that the material had a higher refractive index than the surrounding one, i.e., higher density than the mortar, excluding an air gap. A certain identification of the building elements found in depth in plaster was rather difficult, but their surface profiles have been 3D imaged in detail, demonstrating the high potentials of the technique for identifying hidden subsurface inclusions in lime-based plaster. All of this was possible by combining the proper data processing with the use of 3D visual rendering.

The localization of buried or concealed structures is important in the conservation field, since the presence of degrading, deforming, or moving components inside plaster layers can affect their integrity and, consequently, the conditions of the painting layers. Characterizing position, geometry, and appearance of internal structural elements may also help in understanding the building history and its construction phases, which is valuable information for building archaeology and architecture field.

A THz time domain system was used in 2019 by Catapano et al. [32] for scanning a wall painting "Annunciation" by Fra Angelico, one of the masterpieces of the early Italian Renaissance, located at the Museum of San Marco in Florence, Italy. The system has been used as complementary inspection tool of a multi-technique examination protocol, which included the use of technical photography (fluorescence induced by ultraviolet radiation), infrared refectography, and ground penetrating radar. $\mathrm{THz} \mathrm{C}$-scans allowed for imaging the fine decorative gold lines, the surface cracks, and repaintings in correspondence of painting lacunas. Two-dimensional (2D) time-of-flight plots at increasing depth towards the interior layers of the painting highlighted the presence of in-depth inhomogeneities.

\subsection{Stone Artwork}

In addition to mural paintings, there are other artistic features of architectural art that have been studied with terahertz. In particular, the state of conservation of stone objects [33] has been assessed in the past. In particular, there was a study by Krügener et al. [34] that inspected the conservation of a stone 
medallion which was part of the Castle of Celle (Germany). A number of internal fractures that were not possible to detect by other imaging methods was found in certain areas of this highly deteriorated object, as shown in Figure 2. Furthermore, the same publication reports on the assessment of the restoration process of stone delimitation in a stone windowsill from the St. Peter's Cathedral of Trier.

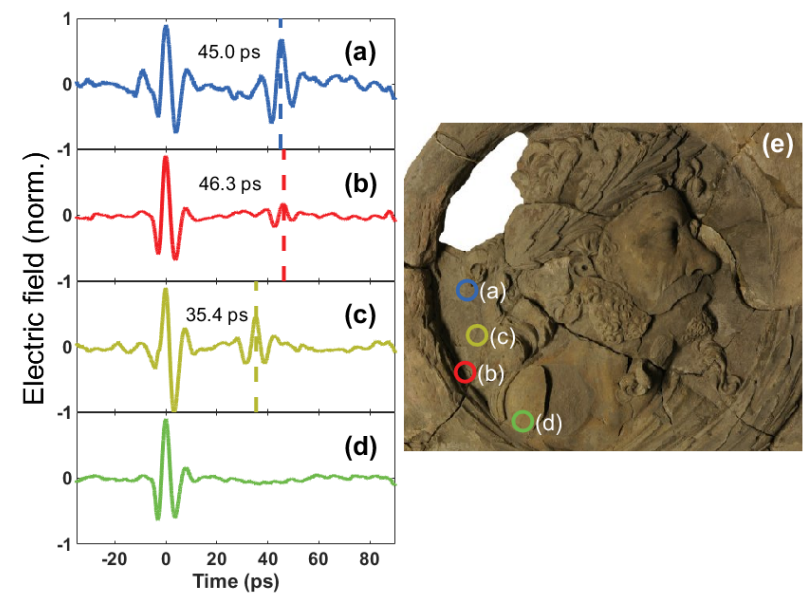

Figure 2. Panels $(\mathbf{a}-\mathbf{d})$ are the reflected terahertz pulses from various locations on the medallion, the positions that correspond to each measurement are marked on panel (e). It is easy to see that the area where points $(\mathbf{a}-\mathbf{c})$ lay presents an internal air gap that generates an echo 35 ps to 45 ps from the surface, which corresponds to a depth of $2.3 \mathrm{~mm}$ to $3.4 \mathrm{~mm}$ from the surface. The measurement at point (d) shows that the stone is solid and has no internal structure at that position [34].

\subsection{Stucco Reliefs}

Yet, another form of architectural decorations that have been studied with terahertz are stucco reliefs [35]. In 2017 Cheung Hoi Ching and coworkers presented a study in which the stucco relief from "Le Musée des Beaux-Arts de Strasbourg", which is a piece from the XV century was analyzed. The artwork is from the artist Antonio Rossellino and it is titled "The Virgin and Child, with Saint John the Baptist and two angels". The authors were able to find different interfaces that they attributed to cracks within the art piece.

\subsection{Clay Decorations}

In 2017, a study of the deterioration state of glazed terracota medallions from a XVI century house in Lüneburg, Germany, as shown in Figure 3a,b using THz ToF was reported [36]. These architectural decorations were common at that time in Germany. The clay decorations, which were glazed with a colour and varnish layer have undergone weather related deterioration for over 400 years, showing the delamination of the glazing layer, which gives them their bright and colorful appearance. The study successfully reports cross-sectional images of the delaminated layers, and determination of the dimensions of the underlying air gaps, as shown in Figure $3 c$, this was valuable for the restoration process of such objects. 

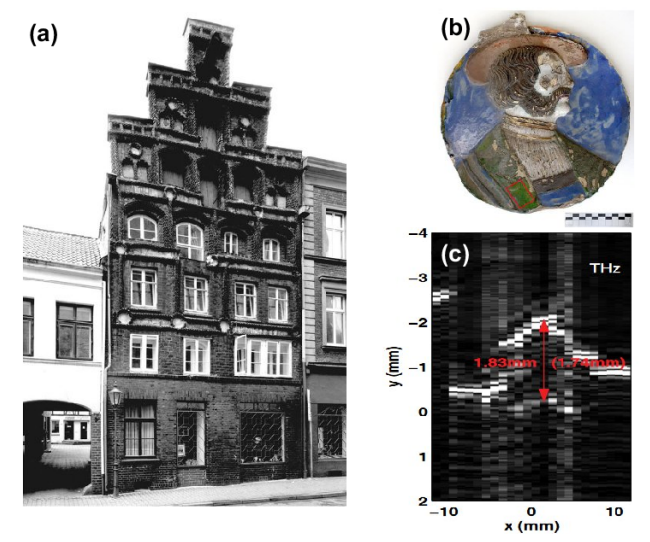

Figure 3. (a) Façade of the townhouse in Lünerstrasse 3, Lüneburg, Lower Saxony where the medallion (shown in b) was removed from for analysis and restoration [photo by Gerhard D'ham]. (b) Polychrome glazed Terracotta medallion-portrait of a man-from the 16th century. The red lines indicate the examined area. (c) A tomographic cut of the air gap obtained from the terahertz time-of-flight measurements. Adapted with permission from Journal of Infrared Millimeter and Terahertz Waves 38, 495 (2017) [36] Adapted with permission from [Journal of Infrared, Millimeter, and Terahertz Waves], Springer, 2017.

\subsection{Paint on Metal Structures}

A rather different type of architectural object are Kiosks. These ornamental constructions which are usually found in the center of main squares, plazas or parks can be found in many parts of the world. The kiosk of Guadajara, Mexico, was studied using terahertz ToF spectroscopy recently [37]. This piece that dates from the end of the XIX century is formed by a structure of cast iron with ornaments made of the same material. The structure has been painted in many occasions for over a century. The terahertz study revealed a number of areas that show delamination between the historically accumulated paint layers, it was also possible to determine that the appearance of delamination correlates with the position in the structure, being more frequent on the eastern side than the western side, which can be explained as increased mechanical stress that is caused by the early morning sun rays heating up the outer paint layers that are on the cold iron core, which does not happen on the western side as the object heats up more slowly and evenly during the day.

\section{Structural Integrity Inspection Of Buildings}

As mentioned earlier, the inspection of the structural integrity of buildings is also a very important aspect. [38] Terahertz imaging has been proven useful in finding voids in concrete samples, as depicted in Figure 4 [39]. Other studies have reported the inspection of defects in materials as varied as wood, cement, and tile adhesives, which have been imaged with terahertz [40] (see Figure 5b,c). The use of water percolation process in cracks has been used to enhance the contrast in order to find them, as shown in Figure 5a,b. We finally want to mention that the THz-optical properties of a number of common building materials have been reported [41,42]. These properties are fundamental for the appropriate analysis and understanding of many of the studies that we have reviewed here, and some that may come in the future. 

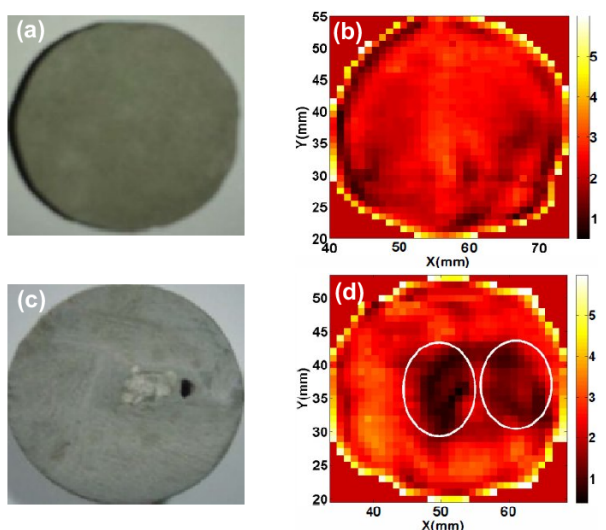

Figure 4. (a) Photograph and (b) terahertz image of a defect-free concrete sample. (c) Photograph and (d) terahertz image of a concrete sample with defects. Adapted with permission from 38th International Conference on Infrared, Millimeter, and Terahertz Waves (IRMMW-THz) [39]. Adapted with permission from [38th International Conference on Infrared, Millimeter, and Terahertz Waves], IEEE, 2013.

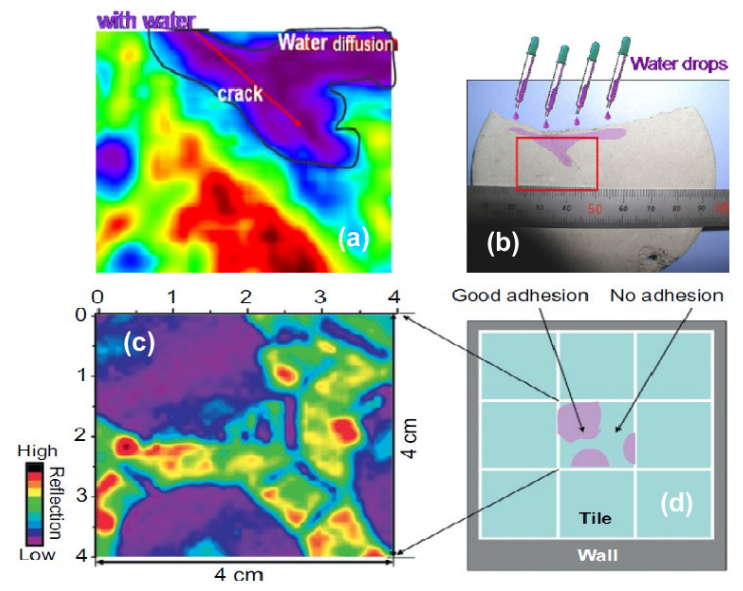

Figure 5. (a) Terahertz imaging of cracks in concrete, in which water diffuses along the cracks which enhances the detection sensitivity of the defect. (b) Is an illustration that depicts the process of water percolation which increases the contrast around the crack. (c) Is a terahertz image of the voids of the adhesive cement under a tile. (d) illustrates the geometry of the measurement shown in (c) [40]. Adapted with permission from [NDT \& E International], Elsevier, 2009.

It is worth pointing out that there is still a broad number of construction materials that have not been properly characterized in the terahertz band, and this is a pending task that will be of importance not only in building measurements, but in other areas, like terahertz telecommunications. Terahertz waves have also been used as non-contact inspection tool for measuring the water content of concrete, which is an important parameter in terms durability of structures made from it $[43,44]$. Furthermore, terahertz has been used to characterize metal objects. It has been demonstrated to provide quantitative information on the roughness of archeological metal surfaces [45] and for distinguishing corroded/mineralized layers in metal artifacts [46]. 


\section{Monitoring of the Conservation Process of a Mural}

An original study that we present as part of this contribution is the evaluation of the restoration process of the mural paintings of the Konstantinbasilika (The Basilica of Constantius). The Basilica was built in the III and IV centuries by the Roman emperors Constantius (293-306) and Constantine (306-337) as a reception hall of the imperial palace. This large Roman building has evolved from being a castle to episcopal residence and protestant church (since 1856). On it, remain some of its colorful Roman facade decorations, primarily found in the window reveals. As part of a varied history, the Konstantinbasilika has undergone many architectural changes. During the restoration of the building in the XIX century, the remaining Roman plaster and painting fragments of the facade were uncovered. Only a few connected plastered areas survived to this day. This includes larger original plasterwork in the northeast. They show a warm, flat white tone with dividing painting elements in an intense red. In addition, larger painted surfaces, including remains of floral and figurative decoration, have been preserved in the window reveals of the west side and the apse [47]. These paintings have been exposed to weather deterioration since the XIX century. Yet, different efforts have been made to prevent the deterioration of the paintings as a consequence of color weakening, pigment alteration, mainly owing to the formation of black crusts (sulfation) and the accumulation of dirt as well as climate variations and wind-related erosion.

A series of potential restoration/conservation strategies were evaluated for these mural paintings. It was decided to apply a removable protective cover in order to protect them against further deterioration. A fundamental consideration for this decision was the fact that existing climatic influence on the surfaces can often only be effectively reverted to a limited extent. A protective removable cover, on the other hand, represents an alternative that can preserve the artwork on the long term. The concepts for covering wall paintings for conservation purposes were developed in Germany in the nineteen hundreds, but a systematic follow-up and examination of various techniques is currently a topic of debate and active research. An effort aiming to contribute to this discussion is promoted by some research projects at the Department of Conservation and Restoration of Wall Painting and Architectural Surface of HAWK in Hildesheim, in collaboration with the federal state Rhineland-Palatinate and the Directorate-General for Cultural Heritage. A specific objective is to further develop, adapt, and optimize conservation measures, such as long-term protection of weather-exposed surfaces. For our investigation, we selected an area of the mural of the Basilica, which was in the process of being covered; this section lies on the west facade and was intervened in 2016.

The conservation system was used at the Konstantinbasilika, as shown in Figure 6. The original mural paint was covered by a cyclododecane $\left(\mathrm{C}_{12} \mathrm{H}_{24}\right)$ layer, then a reinforcement with para-aramid fibres (KEVLAR) was placed and finally the sacrificial render layer, made of Roman cement, was applied. Cyclododecane was chosen as the separating layer, because it temporally seals the historical surface but subsequently sublimates without leaving traces on the original artwork. Depending on the processing temperature and the addition of benzine, molten cyclododecane can be applied on a relatively thin layer in order to better match the shape of the covering plaster to the original historic surface. After sublimation, it is assumed that a thin air-gap remains between the original artwork and the new reinforced plaster. In an early series of investigations on the first sample area at the Konstntinbasilika in 2015, a destructive examination of the sublimation of cyclododecane was carried out. A circular drill was used to cut an area from the surface of the protective plaster. The sample removal resulted in severe damage to the reinforcing material; therefore, THz-TDS was used for the first time in 2016 in order to prevent further damage and weakening of the protective plaster. Other methods, such as ultrasonic examination, were not considered because the depth resolution is inappropriate for the small cavities formed. So far, the evolution of the cyclododecane/air layer has never been non-destructively probed on a real sacrificial render system. The aim of our measurements with THz-TDS was to determine the size and dimension of the cyclododecane 
layer and the airgap that forms after its sublimation process between the original surface and the covering sacrificial render system. In this section we present the results of non-destructive measurements performed by terahertz time-domain spectroscopy (THz-TDS) both on mockups and in-situ on the conservation intervened mural of the Konstatninbasilika.

Figure 6 shows the area that we used for monitoring. The images show the mural before the conservation intervention, and the result after the intervention. Aluminum foils can be seen on the surface of the protective plaster layer that were used to generate nearly-perfect terahertz reflections, to be used in the data processing as reference. The stratigraphic measurements were taken in the areas delimited by the aluminium foil squares.
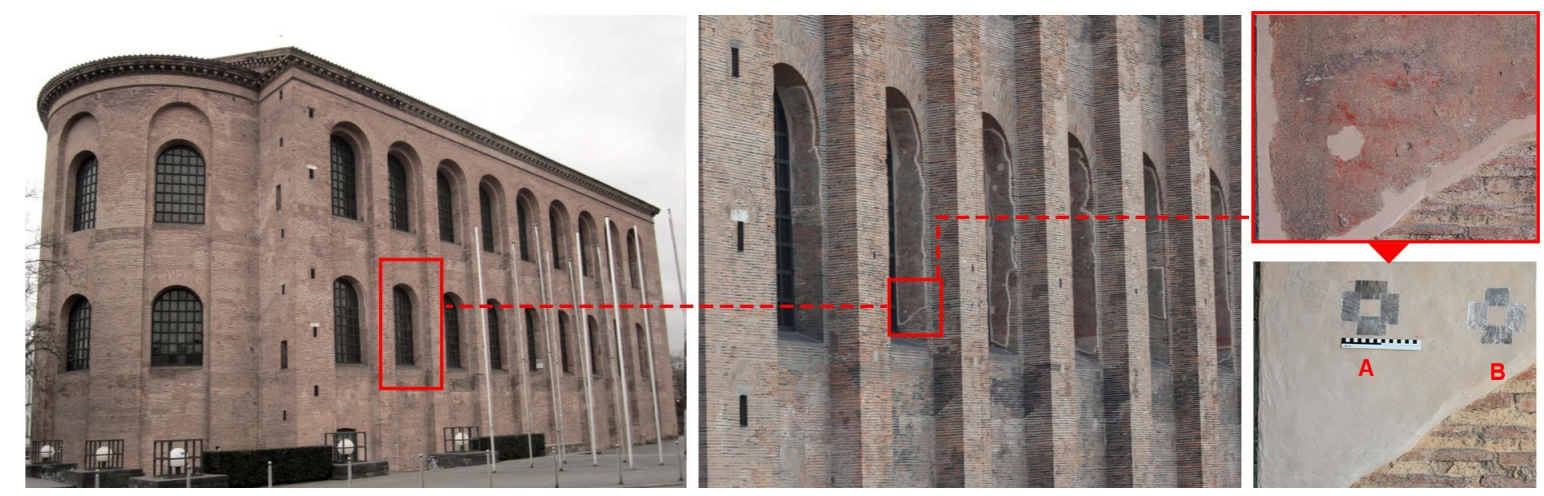

Figure 6. Photographs from the Konstantinbasilika identifying the area where the conservation intervention was performed. The right-hand-side bottom panel shows the area after conservation with the aluminium foil references around the positions studied.

In parallel with the conservation intervention, mockups were fabricated for laboratory measurements. Wooden molds of $14.5 \mathrm{~cm} \times 12 \mathrm{~cm}$ were prepared, a base of Roman cement was placed at the bottom; subsequently, cyclododecane was applied with a brush to the surfaces by double coating reaching a thickness of approximately $0.6 \mathrm{~mm}$, over it a reinforcing mesh made of para-aramid fibres (KEVLAR) was placed. Finally a plaster layer of $\sim 7 \mathrm{~mm}$ up to the edge of the mold was applied. The thickness of the upper protective plaster and the layer of cyclododecane corresponded approximately to the real conservation measure at the Konstantinbasilika. While the mock-ups were kept in a laboratory with a controlled temperature of $\sim 20^{\circ} \mathrm{C}$, the mural was exposed to the uncontrolled outdoor conditions that prevailed in Trier during the year that passed between measurements.

All of the measurements were performed with a fiber-coupled terahertz time-domain spectrometer using a "pitch-catch" terahertz path like the one shown in Figure 1b but using high density polyethylene lenses instead of off-axis parabolic mirrors. The spectrometer is based on a mode-locked ultrafast Er:fiber laser which is used to gate both, an emitting and a receiving, photoconductive antennas. The transceiver ensemble was mounted on an " $x-y$ " motorized stage that allowed automated multiple point measurements.

Various measurements over the course of 300 days were taken on the mockups. A typical terahertz waveform from one of the mockups is shown in Figure 7a, the first pulse, at $t=0$, corresponds to the air-plaster interface, while the second pulse corresponds to a superposition of two echoes from the gap initially generated by the cyclododecane layer. By using sparse deconvolution [48] on the signal, we obtain the impulse response function shown in Figure $7 \mathrm{~b}$, where it is clear that the second pulse is actually the superposition of two echoes, which are shown in more detail in Figure 7c. The separation between these two echoes depends on the physical separation between the plasters as well as the refractive index of the material in between. Therefore if the cyclododecane, whose refractive index is $n \sim 1.53 \pm 0.02$ with 
negligible dispersion, sublimates as expected over the course of several months, the separation between these two echoes is expected to decrease. The separation between echoes as function of time after the sample preparation is shown in Figure 7d. From an exponential fit as function of time $\mathrm{T}$ of the form

$$
\Delta t(T)=T_{\infty}+T_{i} e^{-T / \tau},
$$

where the parameters $T_{\infty}, T_{i}$ and they were obtained for each data set finding that the parameter $\Delta t$ decays with a time constant of $\tau=111 \pm 26$ days, which implies that the sublimation half-life of the cyclododecane under those conditions is $t_{1 / 2}=76 \pm 18$ days. The disappearance of the cyclododecane layer was confirmed by cutting the samples after the experiment and taking micrographs, such as the one shown in Figure 7e, where a free-space gap can be seen between the two plaster layers.
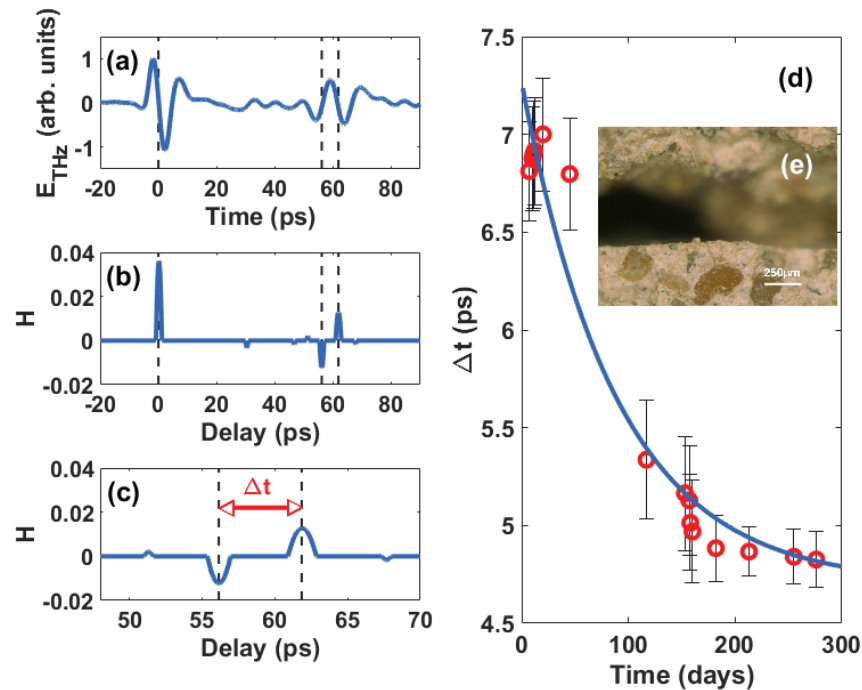

Figure 7. Measurements on a mockup sample. (a) Electric field time-domain signal as function of the delay, the vertical dashed lines show the positions where ecoes were found by using the deconvolved data. (b) Impulse function obtained from sparse deconvolution of the time-domain signal, the vertical dashed lines are provided in order to identify the main features that correspond to the air-mortar reflection, mortar-gap and gap-mortar interfaces. (c) is a closeup of the data in (b) in the 45 to 70 ps window, in which the parameter $\delta \mathrm{t}$ that corresponds to the delay between the two interfaces around the gap is indicated. (d) The evolution of the temporal separation $\delta$ t between the peaks. The evolution is caused by the sublimation of the cyclododecane layer. (e) The micrograph of cross-section of one of the mock-ups showing that the cyclododecane layer disappeared after 300 days.

In situ measurements could not be performed as frequently for practical reasons; however, a set of initial measurements within a few days of the cyclododecane and plaster coating procedure were taken and another set was obtained one year after. The waveforms and deconvolved impulse response functions show a similar pattern to the one from the mockups and the duration of $t$. Measurements were made in two different positions that we identify as A and B, as shown in Figure 6. The separation for the two peaks that correspond to the interfaces around the cyclododecane/air gap changed, in A, from $3.4 \pm 0.3$ ps to $2.8 \pm 0.1 \mathrm{ps}$, and in $\mathrm{B}$, from $4.0 \pm 0.2$ ps to $2.7 \pm 0.1$ ps demonstrating that the cyclododecane content in the layer disappeared, at least partially, leaving an air-gap behind between the original artwork and the protective coating applied. This is consistent with the estimation that we can perform from the mockup 
measurements, which is that between $93 \%$ and $99 \%$ of the cyclododecane would have sublimated over a year.

In conclusion, we were able to monitor the changes of the cyclododecane-plaster material system used for the conservation intervention in-situ at the Konstantinbasilika in Trier, Germany. We could confirm that the cyclododecane layer used as a spacer between the original artwork and the protective plaster coating almost completely disappeared over the course of one year. Furthermore, this is the first report of non-destructive monitoring of the evolution of the cyclododecane layer on mockups, which allowed us to determine that the sublimation half-life of cyclododecane under these conditions is between 58 and 94 days. These numbers are, of course, dependent on the temperature and atmospheric pressure, but they give a good estimate of the times that are involved in the sublimation process. This is, to the best of our knowledge, the first report of an in-situ conservation intervention monitored in a non-destructive way using terahertz time-domain spectroscopy.

\section{Final Remarks}

In this contribution, we presented an overview of the state-of-the-art on the use of terahertz electromagnetic waves for the non-destructive-testing of buildings with particular emphasis on the inspection of architectural art. From the literature review presented, it is clear that terahertz technology opens new and interesting possibilities for the deterioration assessment and conservation process of buildings, both from the structural and artistic point of view. In addition, we presented new results on the inspection of the conservation intervention that took place on the murals of the Konstantiuns Basilika in Trier, Germany. These results show that the layer of cyclododecane, used in the intervention as a spacer between the mural itself, and the protective plaster layer disappeared over the course of a year. Furthermore, we were able to determine that the sublimation half-life of the cyclododecane is of the order of 76 days.

The capacity of terahertz radiation for stratigraphic imaging, its relatively good penetration depth, and innocuity make us foresee that terahertz spectroscopy will continue to find interesting applications in the inspection of both structural and aesthetic aspects of architectural objects. Furthermore, if the costs of this technology maintain their decreasing trend in the coming years, it might even become a common tool for those who routinely perform assessment of architectural objects.

Author Contributions: Conceptualization, W.V., K.K., N.R.-S. and M.K.; methodology, K.K., J.O., L.M.S. and A.J.; software, L.M.S. and A.J.; formal analysis, J.O., L.M.S. A.J. and E.C.-C.; investigation, J.O., K.K. L.M.S. and A.J.; resources, W.V., K.K. and M.K.; data curation, J.O., L.M.S. A.J. and E.C.-C.; writing-original draft preparation, E.C.-C., M.K. and C.L.K.-D.; writing-review and editing, all.; visualization, J.O., L.M.S. A.J. and E.C.-C.; supervision, W.V., M.K. and E.C.-C.; project administration, W.V., M.K. and E.C.-C.; funding acquisition, W.V., K.K. and M.K. All authors have read and agreed to the published version of the manuscript.

Funding: The authors would like to thank the financial support of the Deutsche Bundesstiftung Umwelt (DBU), Germany (Grant 32353/01-45) and the Alexander von Humboldt Foundation through an Experienced Research Fellowship.

Acknowledgments: We thank E. Stübling for providing the material included in Figure 1b,c.

Conflicts of Interest: The authors declare no conflict of interest.

\section{References}

1. Dhillon, S.; Vitiello, M.; Linfield, E.; Davies, A.; Hoffmann, M.C.; Booske, J.; Paoloni, C.; Gensch, M.; Weightman, P.; Williams, G.; et al. The 2017 terahertz science and technology roadmap. J. Phys. D Appl. Phys. 2017, 50, 043001. [CrossRef]

2. Wehrenfennig, C.; Eperon, G.E.; Johnston, M.B.; Snaith, H.J.; Herz, L.M. High charge carrier mobilities and lifetimes in organolead trihalide perovskites. Adv. Mater. 2014, 26, 1584-1589. [CrossRef] [PubMed] 
3. Kindt, J.; Schmuttenmaer, C. Far-infrared dielectric properties of polar liquids probed by femtosecond terahertz pulse spectroscopy. J. Phys. Chem. 1996, 100, 10373-10379. [CrossRef]

4. Castro-Camus, E.; Palomar, M.; Covarrubias, A. Leaf water dynamics of Arabidopsis thaliana monitored in-vivo using terahertz time-domain spectroscopy. Sci. Rep. 2013, 3, 1-5. [CrossRef]

5. Zeitler, J.A.; Shen, Y.C. Industrial applications of terahertz imaging. In Terahertz Spectroscopy and Imaging; Springer: Berlin/Heidelberg, Germany, 2012; pp. 451-489.

6. Fukunaga, K. Thz Technology Applied to Cultural Heritage in Practice; Springer: Berlin/Heidelberg, Germany, 2016.

7. Smith, P.R.; Auston, D.H.; Nuss, M.C. Subpicosecond photoconducting dipole antennas. IEEE J. Quantum Electron. 1988, 24, 255-260. [CrossRef]

8. Grischkowsky, D.; Keiding, S.; Van Exter, M.; Fattinger, C. Far-infrared time-domain spectroscopy with terahertz beams of dielectrics and semiconductors. JOSA B 1990, 7, 2006-2015. [CrossRef]

9. Jepsen, P.U.; Cooke, D.G.; Koch, M. Terahertz spectroscopy and imaging-Modern techniques and applications. Laser Photonics Rev. 2011, 5, 124-166. [CrossRef]

10. Hu, B.B.; Nuss, M.C. Imaging with terahertz waves. Opt. Lett. 1995, 20, 1716-1718. [CrossRef]

11. Chan, W.L.; Deibel, J.; Mittleman, D.M. Imaging with terahertz radiation. Rep. Prog. Phys. 2007, 70, 1325. [CrossRef]

12. Stubling, E.M. Entwicklung und Charakterisierung eines Roboter-Basierten Terahertz-Zeitbereichsspektrometers für Bildgebende Anwendungen auf dem Gebiet der Anthropologie und Kunstrestaurierung. Ph.D. Thesis, Philipps-Universität Marburg: Marburg, Germany, 2019.

13. Wilk, R.; Mikulics, M.; Biermann, K.; Künzel, H.; Kozma, I.Z.; Holzwarth, R.; Sartorius, B.; Mei, M.; Koch, M. $\mathrm{THz}$ time-domain spectrometer based on LT-InGaAs photoconductive antennas exited by a $1.55 \mu \mathrm{m}$ fibre laser. In Proceedings of the Conference on Lasers and Electro-Optics, Optical Society of America, Baltimore, MD, USA, 6-11 May 2007; p. CThR2.

14. Stübling, E.M.; Rehn, A.; Siebrecht, T.; Bauckhage, Y.; Öhrström, L.; Eppenberger, P.; Balzer, J.C.; Rühli, F.; Koch, M. Application of a robotic THz imaging system for sub-surface analysis of ancient human remains. Sci. Rep. 2019, 9, 1-8. [CrossRef]

15. Hernandez-Cardoso, G.; Rojas-Landeros, S.; Alfaro-Gomez, M.; Hernandez-Serrano, A.; Salas-Gutierrez, I.; Lemus-Bedolla, E.; Castillo-Guzman, A.; Lopez-Lemus, H.; Castro-Camus, E. Terahertz imaging for early screening of diabetic foot syndrome: A proof of concept. Sci. Rep. 2017, 7, 42124. [CrossRef] [PubMed]

16. Mittleman, D.M.; Hunsche, S.; Boivin, L.; Nuss, M.C. T-ray tomography. Opt. Lett. 1997, 22, 904-906. [CrossRef]

17. Schmitt, J.M. Optical coherence tomography (OCT): A review. IEEE J. Sel. Top. Quantum Electron. 1999, 5, 1205-1215. [CrossRef]

18. Stübling, E.; Bauckhage, Y.; Jelli, E.; Fischer, B.; Globisch, B.; Schell, M.; Heinrich, A.; Balzer, J.; Koch, M. A THz tomography system for arbitrarily shaped samples. J. Infrared Millim. Terahertz Waves 2017, 38, 1179-1182. [CrossRef]

19. Stubbs, J.H.; Makaš, E.G. Architectural Conservation in Europe and the Americas; John Wiley \& Sons: Hoboken, NJ, USA, 2011.

20. Kennedy, C.J. The role of heritage science in conservation philosophy and practice. Hist. Environ. Policy Pract. 2015, 6, 214-228. [CrossRef]

21. Aubert, M.; Lebe, R.; Oktaviana, A.A.; Tang, M.; Burhan, B.; Jusdi, A.; Hakim, B.; Zhao, J.X.; Geria, I.M.; Sulistyarto, P.H.; et al. Earliest hunting scene in prehistoric art. Nature 2019, 576, 442-445. [CrossRef]

22. Insall, D.W.; Larson, J. Art Conservation and Restoration-Wall Paintings. Available online: https://www.britannica. $\mathrm{com} / \mathrm{art} /$ art-conservation-and-restoration/Paintings-on-ivory (accessed on 10 March 2020).

23. Walker, G.C.; Jackson, J.B.; Giovannacci, D.; Bowen, J.W.; Delandes, B.; Labaune, J.; Mourou, G.; Menu, M.; Detalle, V. Terahertz analysis of stratified wall plaster at buildings of cultural importance across Europe. In Proceedings of the Optics for Arts, Architecture, and Archaeology IV. International Society for Optics and Photonics, Munich, Germany, 15-16 May 2013; Volume 8790, p. 87900H.

24. Jackson, J.; Mourou, M.; Whitaker, J.; Duling, I., III; Williamson, S.; Menu, M.; Mourou, G. Terahertz imaging for non-destructive evaluation of mural paintings. Opt. Commun. 2008, 281, 527-532. [CrossRef] 
25. Fukunaga, K.; Hosako, I.; Kohdzuma, Y.; Koezuka, T.; Kim, M.J.; Ikari, T.; Du, X. Terahertz analysis of an East Asian historical mural painting. J. Eur. Opt. Soc.-Rapid Publ. 2010, 5. [CrossRef]

26. Walker, G.C.; Bowen, J.W.; Matthews, W.; Roychowdhury, S.; Labaune, J.; Mourou, G.; Menu, M.; Hodder, I.; Jackson, J.B. Sub-surface terahertz imaging through uneven surfaces: Visualizing Neolithic wall paintings in Çatalhöyük. Opt. Express 2013, 21, 8126-8134. [CrossRef]

27. Fukunaga, K.; Meldrum, T.; Zia, W.; Ohno, M.; Fuchida, T.; Blümich, B. Nondestructive investigation of the internal structure of fresco paintings. In Proceedings of the 2013 Digital Heritage International Congress (DigitalHeritage), Marseille, France, 28 October-1 November 2013; IEEE: Piscataway, NJ, USA, 2013; Volume 1, pp. 81-88.

28. ACS. Ancient Roman Man Hidden Beneath Famous Painting at the Louvre, ScienceDaily. Available online: http:/ / www.sciencedaily.com/releases/2013/04/130410154622.htm (accessed on 4 August 2015).

29. Radpour, R.; Bajwa, N.; Garritano, J.; Sung, S.; Balonis-Sant, M.; Tewari, P.; Grundfest, W.; Kakoulli, I.; Taylor, Z. THz imaging studies of painted samples to guide cultural heritage investigations at the Enkleistra of St. Neophytos in Paphos, Cyprus. In Terahertz Emitters, Receivers, and Applications V; International Society for Optics and Photonics: San Diego, CA, USA, 2014; Volume 9199, p. 91990Q.

30. Inuzuka, M.; Kouzuma, Y.; Sugioka, N.; Fukunaga, K.; Tateishi, T. Investigation of layer structure of the takamatsuzuka mural paintings by terahertz imaging technique. J. Infrared Millim. Terahertz Waves 2017, 38, 380-389. [CrossRef]

31. Dandolo, C.L.K.; Jepsen, P.U. Wall painting investigation by means of non-invasive terahertz time-domain imaging (THz-TDI): Inspection of subsurface structures buried in historical plasters. J. Infrared Millim. Terahertz Waves 2016, 37, 198-208. [CrossRef]

32. Catapano, I.; Ludeno, G.; Cucci, C.; Picollo, M.; Stefani, L.; Fukunaga, K. Noninvasive Analytical and Diagnostic Technologies for Studying Early Renaissance Wall Paintings. Surv. Geophys. 2019, 41, 669-693. [CrossRef]

33. Schwerdtfeger, M.; Castro-Camus, E.; Krügener, K.; Viöl, W.; Koch, M. Beating the wavelength limit: Three-dimensional imaging of buried subwavelength fractures in sculpture and construction materials by terahertz time-domain reflection spectroscopy. Appl. Opt. 2013, 52, 375-380. [CrossRef] [PubMed]

34. Krügener, K.; Schwerdtfeger, M.; Busch, S.F.; Soltani, A.; Castro-Camus, E.; Koch, M.; Viöl, W. Terahertz meets sculptural and architectural art: Evaluation and conservation of stone objects with T-ray technology. Sci. Rep. 2015, 5, 1-7. [CrossRef] [PubMed]

35. Ching, M.C.H.; Giovannacci, D.; Gariani, G.; Brissaud, D.; Leroux, L.; Goubard, F.; Bouquillon, A.; Bormand, M. 3D internal reconstruction by the use of terahertz time domain imaging (THz-TDI): An application on a 15th century stucco relief. In Optics for Arts, Architecture, and Archaeology VI; International Society for Optics and Photonics: San Diego, CA, USA, 2017; Volume 10331, p. 103310K.

36. Krügener, K.; Busch, S.F.; Soltani, A.; Castro-Camus, E.; Koch, M.; Viöl, W. Non-destructive analysis of material detachments from polychromatically glazed terracotta artwork by $\mathrm{THz}$ time-of-flight spectroscopy. J. Infrared Millim. Terahertz Waves 2017, 38, 495-502. [CrossRef]

37. Lambert, F.; Reyes-Reyes, E.; Hernandez-Cardoso, G.; Gomez-Sepulveda, A.; Castro-Camus, E. In situ Determination of the State of Conservation of Paint Coatings on the Kiosk of Guadalajara Using Terahertz Time-Domain Spectroscopy. J. Infrared Millim. Terahertz Waves 2020, 41, 355-364. [CrossRef]

38. Abina, A.; Puc, U.; Jeglič, A.; Zidanšek, A. Applications of terahertz spectroscopy in the field of construction and building materials. Appl. Spectrosc. Rev. 2015, 50, 279-303. [CrossRef]

39. Dash, J.; Ray, S.; Nallappan, K.; Sasmal, S.; Pesala, B. Non-destructive inspection of internal defects in concrete using continuous wave 2D terahertz imaging system. In Proceedings of the 2013 38th International Conference on Infrared, Millimeter, and Terahertz Waves (IRMMW-THz), Mainz, Germany, 1-6 September 2013; IEEE: Piscataway, NJ, USA, 2013; pp. 1-2.

40. Oyama, Y.; Zhen, L.; Tanabe, T.; Kagaya, M. Sub-terahertz imaging of defects in building blocks. Ndt E Int. 2009, 42, 28-33. [CrossRef]

41. Piesiewicz, R.; Jansen, C.; Wietzke, S.; Mittleman, D.; Koch, M.; Kürner, T. Properties of building and plastic materials in the THz range. Int. J. Infrared Millim. Waves 2007, 28, 363-371. [CrossRef] 
42. Piesiewicz, R.; Kleine-Ostmann, T.; Krumbholz, N.; Mittleman, D.; Koch, M.; Kürner, T. Terahertz characterisation of building materials. Electron. Lett. 2005, 41, 1002-1004. [CrossRef]

43. Tanabe, T.; Kanai, T.; Kuroo, K.; Nishiwaki, T.; Oyama, Y. Non-contact Terahertz Inspection of Water Content in Concrete of infrastructure buildings. World J. Eng. Technol. 2018, 6, 275-281. [CrossRef]

44. Federici, J.F. Review of moisture and liquid detection and mapping using terahertz imaging. J. Infrared Millim. Terahertz Waves 2012, 33, 97-126. [CrossRef]

45. Cacciari, I.; Siano, S. Use of THz Reflectometry for roughness estimations of archeological metal surfaces. J. Infrared Millim. Terahertz Waves 2017, 38, 503-517. [CrossRef]

46. Jackson, J.B.; Labaune, J.; Bailleul-Lesuer, R.; D’Alessandro, L.; Whyte, A.; Bowen, J.W.; Menu, M.; Mourou, G. Terahertz pulse imaging in archaeology. Front. Optoelectron. 2015, 8, 81-92. [CrossRef]

47. Riedl, N. Wandmalerei in freier Bewitterung. Konservatorische Herausforderungen am UNESCO- Weltkulturerbe Konstantinbasilika Trier-eine Einführung. ICOMOS_Hefte des Deutschen Nationalkomitees 2013, 55, 12-20.

48. Dong, J.; Locquet, A.; Melis, M.; Citrin, D. Global mapping of stratigraphy of an old-master painting using sparsity-based terahertz reflectometry. Sci. Rep. 2017, 7, 1-12. [CrossRef]

(C) 2020 by the authors. Licensee MDPI, Basel, Switzerland. This article is an open access article distributed under the terms and conditions of the Creative Commons Attribution (CC BY) license (http:/ / creativecommons.org/licenses/by/4.0/). 